\title{
Tráfico de drogas, trabalho e mulheres encarceradas
}

\author{
Drug trafficking, labor and imprisoned women
}

Marta Bramuci de Freitas ${ }^{1}$

Ana Elizabeth Santos Alves ${ }^{2}$

\begin{abstract}
RESUMO
O objetivo é apresentar uma análise sobre o trabalho no tráfico de drogas no Brasil, considerando a elevação do percentual de mulheres encarceradas em razão desse crime. Para comprovar as nossas análises, apresentamos trechos de relatos das mulheres internas, em uma unidade prisional do interior do estado da Bahia, sobre o trabalho no tráfico de drogas.
\end{abstract}

PALAVRAS-CHAVE: Mulheres Encarceradas. Trabalho no Tráfico de Drogas. Memórias.

\begin{abstract}
The objective is to present an analysis of the work in the drug trafficking in Brazil, considering the elevation of the percentage of women incarcerated because of this crime. To prove our analysis, we present excerpts of reports of internal women, in a prison unit of the interior of the state of Bahia, on the work in drug trafficking.
\end{abstract}

KEYWORDS: Imprisoned Women. Work in Drug Trafficking. Memoirs.

O tráfico de drogas é o crime com o maior número de incidências penais no Brasil, representando $28 \%$ do total de registros. Os crimes de roubo e furto somam $37 \%$ das incidências e os homicídios representam $11 \%$. Em relação ao número total de detentos, a proporção de presos por tráfico de drogas é maior. Entre os homens, essa modalidade de crime significa $26 \%$ dos registros. Entre as mulheres, o percentual atingiu $62 \%$, um índice bastante alto, uma vez que $28 \%$ das encarceradas respondem por crimes de outra natureza (INFOPEN, jun./2016).

\footnotetext{
${ }^{1}$ Universidade Estadual do Sudoeste Baiano - UESB. E-mail: bramuci.a.s@gmail.com.

2 Doutorado em educação pela Universidade Federal da Bahia (2002). Profa. Da Universidade Estadual do Sudoeste da Bahia.
} 
Na década de 1990, 176.691 pessoas estavam presas por tráfico de drogas no Brasil. Dessas, 155.699 eram homens e 21.022 mulheres. Dados de junho de 2016 apontam um aumento desse quantitativo. Segundo os registros, nesse ano, havia 726.712 pessoas privadas de liberdade, 42.355 do sexo feminino e 665.482 do sexo masculino, o que representa um aumento da ordem de 707\% em relação a1990 (INFOPEN, jun./2016).

O contexto do tráfico de drogas (produção, comercialização e consumo) é alvo de amplas discussões em todo o mundo, uma vez que essa modalidade de comércio proporcionou a abertura de mercados e tornou-se um negócio lucrativo.

O comércio de drogas representa uma alternativa para a inserção e a permanência de mulheres e homens em uma ocupação que invade o processo do trabalho informal. Na fronteira "entre o legal, o ilegal, também entre o ilícito e delituoso" (TELLES, 2009, p. 158), essa atividade contribui para a expansão das redes de subcontratação. Nesse contexto, podemos situar a ampla participação de mulheres especialmente as mais pobres e com baixo nível de escolaridade, em ocupações informais e precárias. O comércio de drogas é o principal responsável pelo ingresso de mulheres no sistema penal brasileiro. Conforme explicita Novaes (2010), o elevado índice de condenações por tráfico de drogas entre a população feminina atingiu um nível preocupante.

$\mathrm{O}$ alto número de sentenças entre as mulheres tem relação com as complexas condições políticas e econômicas do país. O aumento das desigualdades sociais e a perda dos direitos sociais acentuam os níveis de pobreza e atingem especialmente o público feminino.

As relações de trabalho no tráfico de drogas orientam-se pela subordinação ao mercado e conforme a reorganização do capital, elas se transformam, gerenciadas pela lógica capitalista. O objetivo é o lucro e o poder, como explica Feffermann (2006, p.15): “[...] existe um consenso de que se está diante de uma das indústrias mais lucrativas do mundo, ultrapassando até a petrolífera”.

As reflexões apresentadas neste artigo fazem parte da dissertação de mestrado "Memórias das mulheres encarceradas e o trabalho no tráfico de drogas", desenvolvida por uma das autoras deste texto, e tratam da sua 
vivência na condição de assistente social de uma unidade prisional do interior do Estado da Bahia. A pesquisa foi desenvolvida entre os anos de 2014 e 2016. O objetivo foi compreender as memórias trazidas por essas mulheres sobre a sua inserção e permanência no trabalho desenvolvido no tráfico. Especificamente, o propósito é conhecer o cotidiano dentro da unidade, descrever as condições de vida das encarceradas e analisar o relato das suas memórias. Para tanto, selecionamos sete mulheres para realização de entrevistas. O critério utilizado foi identificar, entre as internas, aquelas que aguardavam julgamento, acusadas de tráfico de drogas no Brasil, conforme Leis $\mathrm{n}^{0}$ 6.368/76 e $\mathrm{n}^{0} 11.343 / 06^{3}$. Desse grupo, escolhemos uma amostra das que trabalharam no transporte exterior, interestadual e/ou estadual de drogas e que se dispuseram a contar suas histórias de vida.

Neste artigo, apresentamos um recorte da pesquisa. O objetivo é, portanto, analisar de modo breve o trabalho desenvolvido no tráfico de drogas no Brasil, considerando a elevação do percentual de mulheres encarceradas acusadas desse crime. Para comprovar as análises, citamos trechos de entrevistas em que quatro internas da unidade prisional em questão relatam assuas experiências.

\section{O trabalho no tráfico de drogas}

Associado à expansão internacional do capitalismo e à intervenção colonial-militar, o comércio de drogas conseguiu demarcar território ao longo da história, tendo como testemunha a guerra do ópio, resultado do papel da Inglaterra na condição de incentivadora do tráfico de ópio na China do século XIX, assim como das plantações desse narcótico em território indiano.

\footnotetext{
${ }^{3}$ A Lei $n^{\circ}$ 11.343/2006 optou pelo termo "drogas", abandonando quase que integralmente a expressão "substância entorpecente" presente nas Leis n $\mathrm{n}^{\circ}$ 6.368/1976 e n ${ }^{\circ}$ 10.409/2002. O conceito de drogas aparece no parágrafo único de seu art. 10: "Para fins desta Lei, consideram-se como drogas as substâncias ou os produtos capazes de causar dependência, assim especificados em lei ou relacionados em listas atualizadas periodicamente pelo Poder Executivo da União". O art. 66 do mesmo diploma legal estabelece: "Para fins do disposto no parágrafo único do art. $1^{\circ}$ desta Lei, até que seja atualizada a terminologia da lista mencionada no preceito, denominam-se drogas substâncias entorpecentes, psicotrópicas, precursoras e outras sob controle especial, da Portaria SVS/MS n ${ }^{\circ} 344$, de 12 de maio de 1998".
} 
Em 1890, o Brasil já contava com uma política de controle das drogas ${ }^{4}$, amparado no Código Sanitário, que objetivava eliminar as drogas das cidades com base em medidas profiláticas. Contudo, até a década de 1910, o Estado não obteve sucesso nessa tarefa, apesar de contar com uma grande mobilização de moralistas e também da mídia. Nas palavras de Rodrigues (2002), o controle sobre o uso, o consumo e o comércio de determinados tipos de drogas no Brasil iniciou-se a partir de 1921. Seguindo o modelo de Haia ${ }^{5}$, a lei do Brasil previa punição para o uso de substâncias que não fossem prescritas por médicos.

Em função do crescimento do consumo de substâncias ilícitas e do tráfico de drogas nos anos 1970, no período entre 1982 e 1986, a preocupação foi pensar em uma forma de fiscalizar o uso não autorizado desses produtos. Das conferências realizadas pela ONU em Viena, nos anos de 1987 e 1988, surge, portanto, o principal acordo multilateral para combater o problema: a Convenção das Nações Unidas contra o tráfico ilícito de narcóticos e substâncias psicotrópicas.

De acordo com Procópio Filho e Costa Vaz (1997), a Convenção reuniu vários pontos referentes ao combate às drogas e se preocupou também em ajustar termos relacionados à prevenção, à fiscalização e controle, à repressão e a outras formas de cooperação e assistência internacional. Essa passou a ser a principal direção para participar dos planos regionais e subregionais, bem como para o planejamento de políticas nacionais antidrogas.

Nas palavras de Rodrigues (2002), em 1990, o tráfico de drogas passou a ser considerado crime hediondo. Essa denominação o elevou à categoria de crime. Tal como o sequestro, a tortura e o estupro, não permitia aos condenados o direito à fiança e à progressão da pena. Em 2006, revogase a Lei de Tóxicos de 1976 e a Lei no 11.346/2006 institui o Sistema

\footnotetext{
${ }^{4}$ Com fundamento em uma reflexão antropológica, Carneiro (2002, p.116-117) afirma que "as drogas acompanham a história do homem. [...] são necessidades humanas. Seu uso milenar em quase todas as culturas humanas corresponde a necessidades médicas, religiosas e gregárias. Não apenas o álcool, mas, quase todas as drogas são parte indispensável dos ritos de sociabilidade, cura, devoção, consolo e prazer. Por isso, as drogas foram divinizadas em inúmeras sociedades”.

${ }^{5}$ Criada em 1893, e composta atualmente por setenta e sete membros, a Conferência de Haia de Direito Internacional Privado é uma organização intergovernamental integrada por países com diferentes tradições jurídicas. O objetivo é unificar progressivamente as regras de direito internacional privado, por meio de convenções internacionais, em especial nas áreas de direito de família, direito comercial e processual civil. http://www.cjf.jus.br/cjf/noticias/2015/outubro. Acesso em abril de 2018.
} 
Nacional de Políticas Públicas sobre Drogas. Essa Lei extingue a pena de prisão pelo cultivo ou pelo porte de drogas para consumo próprio e diferencia quem trafica para manter o vício (cuja pena foi reduzida) dos que fazem do tráfico uma profissão.

Montoya (2007, p.147) explica que, no Brasil, o narcotráfico6assume outra concepção, diferente dos demais países da América do Sul atravessados pela Cordilheira dos Andes. O Brasil "recebe os efeitos do narcotráfico, devido, principalmente, à extensão de suas fronteiras, que muitas vezes, carecem de vigilância adequada" e à presença do Estado.

Além disso, o Brasil não é mais visto somente como uma rota privilegiada para circulação das drogas, uma vez que também "processa, importa e exporta vários tipos de drogas" (PROCÓPIO e COSTA VAZ, 1997, p.76), de acordo com as demandas do mercado.

Os autores Procópio e Costa Vaz (1997) apresentam ainda fortes motivos de preocupação com o narcotráfico no Brasil. Primeiro, o assunto adquiriu importância política e econômica no contexto regional e internacional, considerando que os problemas com as drogas abrangem todos os países. Assim, tal como ocorreu nos Estados Unidos e na União Europeia, o Brasil incentivou a criação de políticas de combate às drogas. Segundo, o narcotráfico demarcou território em função dos problemas que marcam o contexto brasileiro: debilidade do poder estatal, desemprego, subemprego e variação da economia informal, segregação de camadas sociais no sistema de desenvolvimento, precariedade econômica e social dos habitantes, o acentuado crescimento dos núcleos urbanos e, por último, a associação das classes populares ao universo das drogas, até então um domínio das camadas sociais mais favorecidas.

No que se refere às políticas de combate às drogas, a proibição com força de lei ganhou impulso mundial por intermédio dos Estados Unidos, que passou a reprimir o uso de entorpecentes e a apoiar movimentos, sessões e convenções promovidas pelas Nações Unidas de controle de drogas e outros eventos realizados ao longo dos anos.

\footnotetext{
${ }^{6}$ De acordo com Oliveira (2007, p.8), "O narcotráfico abarca a produção (plantio, processamento), o transporte (nacional, transnacional) e o comércio de substâncias psicoativas consideradas ilícitas pela Comunidade Internacional".
} 
Contudo, uma vez que os objetivos não foram atingidos, promoveu-se a consagração da "guerra às drogas". Essa expressão adquire duplo entendimento. Primeiro, a principal característica de uma guerra, segundo Sica (2005), é seu “estado de exceção", portanto, qualquer medida é válida para liquidar o inimigo comum. Segundo, o termo convoca um expansionismo do poder militar/industrial com o uso de tecnologia própria, espionagem e mecanismos de técnicas bélicas, conforme uma guerra clássica. Desse modo, Maronna (2005) faz uma análise que denota certa discordância desse "combate": os inimigos são, além de meras plantas e substâncias químicas, pessoas que produzem, transportam, comercializam e consomem tais produtos, pessoas que muitas vezes não usam armas.

Em relação ao consumo e ao tráfico de drogas, é possível verificar que, apesar dos altos investimentos, a guerra fracassou. O que se evidencia é um número monumental de encarcerados em função do tráfico.

Na opinião de Karam (2011), esse combate:

[...] não é efetivamente uma guerra contra as drogas. Como qualquer outra guerra, não se dirige contra coisas. É, sim, uma guerra contra pessoas - os produtores, comerciantes e consumidores das arbitrariamente selecionadas substâncias tornadas ilícitas. Mas, é ainda mais propriamente uma guerra contra os mais vulneráveis, dentre esses produtores, comerciantes e consumidores. Os "inimigos" nessa guerra são os pobres, os marginalizados, os desprovidos de poder (KARAM, 2011, p. 54).

A guerra às drogas agrava-se quando o narcotráfico e o traficante passam a ocupar o espaço de adversário social. É visível a discriminação de classe em relação aos traficantes, indivíduos em condição vulnerável, que trabalham para um mercado altamente lucrativo que se sustenta na ilegalidade. Assim, além da segurança pública, a análise referente ao narcotráfico deve perpassar por outros espaços de discussão. A "guerra às drogas" é conveniente para controlar política e socialmente grupos discriminados que devem, portanto, ser retirados da sociedade, tal como ocorre nas ações de combate. Ademais, é inegável o interesse econômico mascarado na política proibicionista. De acordo com Sica (2005), a proibição cria a escassez das drogas no mercado, o que é essencial para regular o preço e valorizar a mercadoria. 
Ao lado dessas questões, existem outras. Para algumas pessoas, a atividade econômica relacionada ao tráfico de drogas no Brasil preenche a lacuna deixada pela falta de perspectiva de vida e alivia o desemprego. Embora ilícito, o tráfico de drogas atrai uma parcela significativa da população brasileira porque permite uma margem de lucro superior ao de outras atividades lícitas. O dinheiro do tráfico permite o acesso a bens e serviços, conforme afirma uma das internas da unidade:

[...] A gente trabalha praticamente um ano para receber o que recebe lá [no tráfico] em praticamente em vinte e quatro horas [...] é só ir ali e fazer uma viagem. É muito dinheiro, entendeu? Enquanto não dá problema é muito bom [...] Comecei com quinze anos [....] (ANGELITA, 21 anos, ensino fundamental) ${ }^{7}$.

Confirmando a teoria de que o tráfico é um meio de suprir os recursos necessários à sobrevivência, a entrevistada relata: “[...] tinha feito um mês que meu marido tinha morrido em uma troca de tiro, eu estava precisando de dinheiro [...]. Eu ia usar o dinheiro para sair do lugar onde eu morava com meu marido, comprar umas coisas [...] (ANGELITA)”.

Portanto, segundo Feffermann (2006, p.37) constrói-se a "cultura da droga" em um espaço social vazio deixado pelo Estado, uma vez que as políticas públicas atendem aos interesses do sistema do capital. Um estudo realizado por essa autora sobre o cotidiano de jovens trabalhadores do tráfico de drogas e o papel do Estado constatou em entrevistas com representantes da segurança pública, a necessidade de uma atuação mais efetiva do poder público, do judiciário e das instâncias de controle social para a concretização dos direitos sociais. "O Estado se descompromete de suas funções sociais, de suas obrigações, os papéis se confundem, os lugares são esvaziados, permitindo que os outros os ocupem" (FEFFERMANN, 2006, p.138).

Dessa forma, sem acesso às políticas públicas, precisando encontrar formas de prover as suas necessidades básicas, a população recorre ao mercado ilícito. De acordo com Telles (2009, p.115), a partir dos anos 1980,

\footnotetext{
${ }^{7}$ Entrevista realizada em 20 de outubro de 2015.
} 
as diferenças entre trabalho, desemprego e expedientes de sobrevivência, invadem os processos produtivos com o trabalho informal.

O aumento do desemprego e a necessidade de sobrevivência da classe trabalhadora abrem espaço para a precarização do trabalho. Nesse contexto, é importante compreender o tráfico de drogas como uma atividade exercida no Brasil e no mundo, que absorve um grande número de pessoas em busca de trabalho, de ascensão, de reconhecimento e valorização social, apesar de desconsiderar a lei.

Ao analisar o trabalho na sociedade capitalista, Castel (2008) afirma que o processo de reestruturação produtiva e a flexibilização das relações de trabalho intensificam a desigualdade social e, fundamentalmente, o desmonte dos direitos conquistados com o surgimento de formas de pobreza e o aumento do desemprego,em face da lógica da acumulação e da valorização do capital.

[...] a situação atual é marcada por uma comoção que, recentemente, afetou a condição salarial: o desemprego em massa e a instabilidade das situações de trabalho, a inadequação dos sistemas clássicos de proteção para dar cobertura a essas condições, a multiplicação de indivíduos que ocupam na sociedade uma posição de supranumerários, 'inempregáveis', inempregados ou empregados de um modo precário, intermitente. De agora em diante, para muitos, o futuro é marcado pelo selo do aleatório (CASTEL, 2008, p.21).

Sem direção, em busca de espaço e de importância no mercado de trabalho, mulheres e homens são lançados de um lado para o outro na estrutura social. Trata-se de indivíduos que transitam entre a instabilidade e a própria não existência social, trabalhadores que, ávidos pela inclusão em algum espaço ou organização, são absorvidos pelo mercado ilícito. Feffermann afirma que "[...] na realidade está-se diante de uma inclusão daqueles que estão sendo alcançados pela nova desigualdade social produzida pelas grandes transformações econômicas e para os quais não há senão, na sociedade, lugares residuais" (2006, p.96). A autora explica que, a partir dos anos 1990, com a flexibilização das formas de gerir e organizar o trabalho, no processo de reestruturação produtiva no Brasil, as atividades 
ilícitas foram-se internacionalizando e se reestruturaram de tal forma que, de um lado, estão os empresários do ilícito (a droga), atuando em rede, e, de outro, o pequeno comerciante atuando na precariedade, à margem da legalidade, transitando entre a atividade ilegítima e a prisão. Conforme a autora:

O tráfico de drogas é o ramo de atividade mais importante do processo de globalidade do crime, embora outros tipos de tráficos sejam efetuados por esse sistema, cujo poder se estende por todo o mundo: armas, tecnologia, materiais radioativos estão interligados pela grande matriz de todos os atos ilícitos [...] O processo de "globalização" da economia foi muito propício para o crime organizado [...]. O tráfico de drogas se transforma em instrumento de poder (FEFFERMANN, 2006, p.37-43).

Esse movimento ganha espaço na mesma proporção em que cresce a demanda (RUGGIERO 2000, apud TELLES, 2009, p.158), o que se denomina "modulação criminosa do capitalismo pós-fordista, criminalidade justintime ${ }^{\mathcal{Q}}$, uma resposta às variações e aos distintos territórios dos mercados.

Feffermann (2006) avalia as condições econômicas, históricas, políticas e sociais de jovens inscritos no narcotráfico e identifica o significado de tráfico de drogas para eles:

Entender-se-á o tráfico como forma de organização aqui denominada de "trabalho" informal e ilegal, que emprega grande número de jovens na sua estrutura. A definição de um dos jovens ratifica esta afirmação: "a boca é trampo, só que é um trampo embaçado [...]” (FEFFERMANN, 2006, p.211).

Ainda segundo a opinião de Feffermann (2006), o fato de os jovens considerarem essa atividade um trabalho explicita as "particularidades do homem burguês, próprias de uma sociedade dominada pela força do capital, pois, eles mesmos se definem como trabalhadores". Essas ideias “[...] são encontradas de forma exacerbada no mundo dos jovens traficantes" (FEFFERMANN, 2006, p.211).

\footnotetext{
${ }^{8}$ Modelo de gestão da produção no qual os insumos são fornecidos apenas no momento em que serão processados (HECKERT; FRANCISCHINI, 1998, p.1).
} 
Diante de tais afirmativas, questionamos: quais seriam as memórias das mulheres encarceradas sobre o trabalho no tráfico de drogas?

\section{Memórias das mulheres encarceradas sobre o trabalho no tráfico de drogas}

As memórias coletiva e social se manifestam nas narrativas de sete mulheres encarceradas em uma unidade prisional do interior da Bahia. Durante as entrevistas, elas tiveram a oportunidade de expor suas histórias de vida. Falaram sobre a memória da família, o trabalho no tráfico e as relações particulares e coletivas. Neste texto, apresentamos relatos de quatro delas.

Para uma melhor compreensão das memórias, partimos das explicações de Halbwachs (2006). Fundador dos estudos referentes à memória na área das ciências sociais, esse autor atribui à memória um caráter coletivo. Suas análises incitam uma visão em torno dessa temática, com base na reflexão do papel da sociedade e dos quadros sociais no ato de lembrar. A memória concretiza-se na reelaboração do passado e por meio de outras reconstruções efetivadas por indivíduos pertencentes ao mesmo grupo.

A construção de significados da memória ocorre no presente de acordo com a rememoração, sujeitando-se a reformulações. O sentido conferido a um acontecimento passado pode passar por transformações a cada rememoração: "as preocupações do momento constituem um elemento de estruturação da memória" (POLLAK, 1992, p.4). Igualmente, a memória das mulheres vai-se ressignificando e, portanto, o requisito para conceituar o tráfico de drogas no contexto atual da interna é o aprisionamento.

Nessa perspectiva, tomada pelas recordações dos contextos vivenciados, e, diante das atuais circunstâncias, uma das mulheres relaciona essa modalidade de trabalho a uma atividade desenvolvida de forma "digna, sem violentar os outros" (MARGARIDA, 42 anos, ensino fundamental) 9. Sem estabelecer uma relação do tráfico de drogas com a criminalidade, com a prática de homicídios e com a destruição de vidas de

\footnotetext{
${ }^{9}$ Entrevista realizada em 27 de abril de 2016.
} 
forma geral, essa atividade passa a ser própria de desocupados. É o que comprova o trecho: "[...] é difícil entender o tráfico de droga como trabalho, trabalho é de gente honesta, de gente que tem o que fazer, de gente como a senhora que tá aqui trabalhando, é de gente honesta que não precisa matar, nem vender droga [...]".

Conforme sugere Margarida, uma das internas, o trabalho tem uma importância social, significa reprodução da vida e realização pessoal. Nessa perspectiva, é fundamental reproduzir o pensamento de Marx (1985, p. 50), que conceitua o trabalho como "uma condição de existência do homem, independente de todas as formas de sociedade, eterna necessidade natural de mediação do metabolismo entre homem e natureza e, portanto, condição da vida humana".

Segundo a entrevistada, as atividades que dignificam mulheres e homens são reconhecidas como trabalho, enquanto o tráfico de drogas não. Questionada sobre de que forma o trabalho "dignifica", conforme a sua história de vida, ela afirma:

Eu trabalhei, mas foi pouco, nunca fui honesta, porque não gostava do trabalho, porque ganhava pouco, sempre pensava no dinheiro, trabalhei no posto [...] sempre em posto, porque eu moro em pista [...] só que eu trabalhei na prefeitura, mas aí eu era contratada, aí o prefeito saiu e saí junto [...], mas isso de um posto para outro, naquela época que não registrava ninguém, era assim minha vida, foi assim minha vida (MARGARIDA).

Ao afirmar que nunca foi honesta, uma vez que julga ser o trabalho uma condição para a construção da identidade, a entrevistada reproduz a ideia que, historicamente, a sociedade formulou sobre a mulher. Quando utiliza o termo "mulher honesta", ela se fundamenta especificamente nos artigos 215 e 216 do Código Penal, que vigorou até a entrada da Lei 11.106/2005. Essa Lei buscou desmembrar da ideia de crime o juízo de valor ao qual a mulher se submeteu.

A entrevistada continua a narrativa afiançando que somente é honesto quem trabalha e que o trabalho "dignifica o homem". E rememora: 
[...] meu pai já é aposentado hoje. Ele teve o próprio bar, lanchonete, trabalhou em uma firma [...] muito boa em São Paulo, porque nós somos daqui, mas moramos em São Paulo, assim, meu pai é muito trabalhador. Depois voltamos com meus avós para a nossa casa aqui, que a gente sempre teve, meu pai trabalhava muito, sempre foi comerciante, meu pai é uma pessoa muito boa. Nossa! Ele já chegava tarde da noite trabalhando, cansado do trabalho, trabalhador, eles são pessoas muito direitas [...]

Em alguns momentos, Margarida insiste em eleger o trabalho como uma atividade desenvolvida por "gente honesta" em uma firma ou, até, informalmente. Mas, novamente, refere-se ao tráfico de drogas como um trabalho, uma forma de receber dinheiro fácil, de ser remunerado sem muito esforço, um estilo de vida:

[...] eu achei que demorava muito para receber e quando me fizeram a proposta eu recebia aquilo em menos de uma semana, em três dias eu já tava com aquele dinheiro, então eu achei mais confortável para mim. Vou trabalhar no crime vou vender droga, vendendo vou conseguir tudo que eu quero, se eu vender, vamos supor duzentos gramas, eu vou ter que pagar pra ele dois mil e quinhentos, mas eu vou fazer dois mil e quinhentos para mim também, é metade, porque aí eu vou saber cortar a droga e empinar a droga que é com caropino ou embalar no papelote dividir, fazer os pacotes e duzentos gramas são muitos petecas, vamos supor que dá cinco mil.

Para as mulheres encarceradas, a definição de trabalho como atividade "honesta, digna, legal e ilegal" está intrinsecamente relacionada ao sentido ideológico do trabalho como algo que "dignifica o homem" (LOCKE, 1999). Essa ideologia oculta a centralidade do tráfico na economia capitalista atual, em que pessoas consideradas de "bem" enriquecem com atividades ilegais e os trabalhadores são responsabilizados pela condição de marginalizados.

É necessário compreender que a uma parte da população o modelo de economia capitalista atribui características, como inclusão precária, situação instável e marginal, pois a própria lógica do mercado estabelece quais serão os indivíduos e grupos com os requisitos necessários à adaptação aos mercados globais e quais serão os excluídos que, automaticamente, ficarão à margem dos seus direitos enquanto cidadãos. 
Pesquisas ${ }^{10}$ analisam o mercado de trabalho no tráfico de drogas e identificam uma estrutura complexa, hierarquizada, com distintos níveis de participação e relevância, o que indica os 'diferentes papéis em suas 'redes', desde as atuações mais insignificantes até as ações absolutamente engajadas e com domínio do fato final" (BOITEUX, 2009, p.39). Quando questionada sobre a relação com membros da rede que ocupam cargos nos altos escalões, Margarida relata:

[...] é uma rede, vamos supor, tem um que mora lá em São Paulo, eu não vou conhecê-lo e geralmente eles não vão querer me conhecer, porque para ele eu sou pequena [...] e como eu sou gerente de um aqui, ele também é gerente lá, [...] normalmente são pessoas que tem carrão, mansões, sítios, tem a casa para disfarçar, porque eles não mexem com nada, eles colocam uma loja no centro, um comércio para disfarçar, uma coisa no shopping, para justificar o ganho, entendeu?

Nessa estrutura, diversos atores se conectam, de forma que as mercadorias circulam entre cada um dos membros da organização, os quais seguem as normas de acordo com o cargo que ocupam.

Moura (2005, p.51) também analisa o tráfico na condição de lugar propício à participação das mulheres: "a precariedade e o desemprego estrutural constituem um dos aspectos fundamentais para a inserção da mulher nesta atividade, pois antes de se constituir numa infração penal, ela é percebida como uma forma e oportunidade de trabalho". Quando perguntamos a Safira de que modo ela compreende essa atividade, a entrevistada responde prontamente:

[...] eu entendo o tráfico como um trabalho, porque a gente entrega um currículo e as pessoas já sabem que a gente trabalhou nessa vida. Eles ficam com medo da gente [...]. Desde nova eu só trabalhei com isso mesmo. Eu nem quis me envolver com trabalho em casa de família [...]. Eu trabalhei dentro de casa, para mim, na casa da minha avó mesmo. Fiz faxina para uma tia, prima. Os outros povos nunca me deram confiança (SAFIRA, 21 anos, ensino fundamental incompleto) ${ }^{11}$.

\footnotetext{
${ }^{10}$ Entre elas, destacam-se Barbosa (1998) e Lemgruber (2003).

11 Entrevista realizada em 27 de abril de 2016.
} 
Diante da falta de perspectiva no mercado, o tráfico de drogas constitui um trabalho como qualquer outro. Safira defende novamente essa prática:

[...] eu também falo, não tenho alternativa, tenho que criar meus filhos. Vou para o tráfico mesmo, quando eu sair, se não achar trabalho, volto para o tráfico. Eu vou procurar, mas acho que eles não vão me dar oportunidade. Vou procurar numas lojas lá embaixo, mas ficam com medo de eu roubar. Eles não vão me dar oportunidade, aí eu volto para o tráfico e no tráfico é até melhor, porque tem outras oportunidades [...] Eu já falei para a advogada e para todo mundo que, quando eu sair daqui, se eu não arranjar um trabalho, eu volto para tráfico [...] (SAFIRA).

Tal como ocorre no caso de Safira, uma parcela considerável de mulheres que adentram na criminalidade já buscou uma oportunidade no mercado de trabalho formal. Entretanto, elas enfrentam dificuldades, inclusive no que se refere às questões salariais. Ademais, as desigualdades de gênero persistem, não obstante a quebra de paradigmas e algumas conquistas sociais, "diferenças nos índices de participação das mulheres segundo os níveis de renda" (ABRAMO, 2007, p. 23). Assim, na busca constante pela própria sobrevivência e pelo sustento de seus dependentes, essas mulheres encontram, no trabalho informal ou ilícito, a única oportunidade de exercer alguma atividade, conforme declara Jade, outra entrevistada: “[...] procurei trabalho e não encontrei, tive que levar essa vida para sustentar meus filhos, eu não podia ver meus filhos com fome [...]. Tentei no lava jato de faxineira, mas eu não consegui” (JADE, 23 anos, ensino fundamental) 12 .

Hirata (1996, p.10) adverte que um trabalhador não apto para a contratação é um trabalhador não capacitado para o emprego. Segundo a autora, "o acesso ou não ao emprego aparece como dependendo da estrita vontade individual de formação, quando se sabe que fatores de ordem macro e microeconômica contribuem decisivamente para essa situação individual”.

As trabalhadoras urbanas, especialmente as moradoras das regiões periféricas das grandes cidades estão inseridas em um contexto assim

\footnotetext{
12 Entrevista realizada em 27 de abril de 2016.
} 
descrito por Telles e Hirata (2007, p.173): “[...] um cenário urbano no qual se expande uma ampla zona cinzenta que tornam incertas e indeterminadas as diferenças entre o trabalho precário, o emprego temporário, expedientes de sobrevivência e das atividades ilegais ou delituosas".

Nessa perspectiva, existem mercados informais considerados legais no âmbito jurídico e mercados informais considerados criminosos, ilegais. Nas práticas sociais, é frequente, portanto, a falta de clareza entre o que se considera delito e o que se caracteriza somente como trabalho informal. Desse modo, o tráfico de drogas é entendido como "trabalho" dentro do chamado mercado informal. Apesar da ilegalidade, essa atividade se torna uma “opção".

Para a maioria das entrevistadas, é confuso definir "trabalho". Ora elas o consideram uma atividade formal e legal, ora definem o tráfico de drogas como trabalho. Esse último caso ocorre quando a atividade justifica a necessidade de prover a mantença da família. Jade continua com o relato: "Eu estava trabalhando no tráfico, meus filhos ficavam na creche [...] Entrei para o tráfico porque eu preciso, eu era menor e ninguém me dava trabalho [...]”. Em seguida, a entrevistada define o que é trabalho:

O tráfico de drogas não é um trabalho, eu considero como trabalho: trabalho honesto, que a gente pega uma vassoura ali e varre, passa um pano na casa, lava um prato e assim vai. Vida de tráfico não é trabalho [...]. O tráfico é um vício. Eu não sei nem responder (JADE).

Assim, em algumas circunstâncias, a atividade no tráfico é denominada trabalho, principalmente quando a ideia de trabalho se relaciona unicamente a "trabalho honesto." Conforme evidenciam tais relatos, a definição de trabalho no tráfico de drogas apresenta traços similares à concepção de trabalho no capitalismo, ou seja, trata-se de uma atividade subordinada aos ditames do mercado, em que, diariamente, trabalhadores se transformam em mercadorias, com valores de uso e de troca, quando necessário.

Segundo Zaitch (2002), as relações de trabalho no narcotráfico caracterizam-se por um elevado nível de flexibilidade. Realiza-se boa parte 
das tarefas por meio de subcontratação para deslocar o risco financeiro e permitir a integração vertical. Pessoas são contratadas para operações específicas ou para diversas operações. A remuneração também é flexível, conforme declaração de Safira:

[...] continuei trabalhando no tráfico. Os filhos continuaram com o pai. O dinheiro que eu recebia eu mandava para eles, ia vê-los e levava dinheiro e ele nunca perguntou de onde vinha o dinheiro. Quando a gente veio de Belo Horizonte, eu disse que não ia mexer mais com tráfico. Só que eu fiquei nessa, para ele só sustentar nossos dois filhos ia ser muito pesado, eu tenho que fazer alguma coisa. Foi na hora que o cara chegou e perguntou para mim se eu queria trabalhar para ele de novo, aí eu fui [...].

Safira sente-se na obrigação de garantir o mínimo de assistência material aos filhos, mesmo quando estes estão sob os cuidados do pai. Percebemos claramente na maioria das entrevistas que o compromisso maior das mulheres é atender às necessidades mínimas dos filhos, que, na maioria das vezes, estão sob sua responsabilidade.

A única fonte de renda das entrevistadas é o tráfico de drogas e, uma vez que não lhes falta disposição, também não lhes falta trabalho. A força de trabalho potencial e o ânimo presentes em adultos, jovens e adolescentes são exatamente a condição exigida pelos gerenciadores das redes do narcotráfico para desenvolver ações ilegais, conforme narra Safira:

[...] nessa época, quando eu comecei, ganhava duzentos reais, ele falou bem assim, não vai ser igual àquela época que você vendia e de cada pedra e maconha você ganhava um real. Agora eu te pago duzentos reais e você vende para mim. Aí eu tirava cinquenta reais para mim e comprava cento e cinquenta reais de coisas para eles. Quando eu não comprava as coisas, eu levava o dinheiro e entregava para o pai deles, toda semana. Quando eu não queria trabalhar, eu pegava os meninos para ficar o final de semana comigo. Quando o cara falava: hoje você vai trabalhar. Eu entregava os meninos de volta. Casa e aluguel eram tudo por conta do cara. Só ficava para mim a água, a luz. Geralmente eles pagam o aluguel. Aqui é assim, ele pagava o aluguel para mim. 
Tal como outras mulheres entrevistadas para esta pesquisa, Safira faz parte de um contingente que, conforme Marx (2008) é o mais profundo sedimento da superpopulação relativa que está na esfera do pauperismo. De forma mais abstrata, temos os vagabundos, delinquentes, prostitutas, o "lumpemproletariado" propriamente dito. Esse grupo se distribui em três camadas: primeiro, os aptos para o trabalho, dispensados em momento de crise; segundo, os órfãos e crianças indigentes, que podem ser utilizados em tempos de prosperidade; terceiro, os degradados, maltrapilhos e incapacitados para o trabalho.

Com base nessa perspectiva, é possível dizer que nesse grupo explorado pelo tráfico de drogas estão os delinquentes, que somam o lumpemproletariado, considerando que fazem parte de uma classe não incluída no mercado ilícito de trabalho. Grande parte dessa população, formada na maioria por jovens, trabalhadores do narcotráfico, já não faz mais parte do exército de reserva ${ }^{13}$, pois está à margem de qualquer relação com o trabalho legal.

Segundo Neto (2013, p.35), o "lumpemproletariado" é formado por "uma parcela da classe trabalhadora totalmente degradada socialmente e que não está disponível para o assalariamento pelo capital". São os criminosos, as prostitutas, os mendigos. Na contemporaneidade, incluem־se nesse grupo os traficantes, os dependentes químicos, as crianças de rua e uma massa humana atingida negativamente pelo capitalismo. $\mathrm{O}$ lumpemproletariado resulta da pobreza absoluta e permanente de grande parte da classe trabalhadora. Esse grupo exclui qualquer possibilidade de existência digna e concentra grande parte da população, condenada à marginalidade, inapta a assumir o trabalho assalariado ou qualquer outro tipo de atividade.

\section{Considerações finais}

Os relatos das experiências da maioria das mulheres internas de uma unidade prisional do interior do Estado da Bahia indicam que elas foram

\footnotetext{
${ }^{13}$ Marx (1985) designou como exército industrial de reserva um contingente populacional disponível, apto a entrar no mercado de trabalho a qualquer momento, em suas fases de expansão, cujo papel seria o de disciplinador da classe operária.
} 
exploradas pelo tráfico exatamente por fazerem parte de um público extremamente vulnerável em função do gênero e da classe social. A divisão sexual do trabalho no tráfico de drogas estabelece, para as mulheres, postos secundários, para os quais não se exige qualificação, apenas alguma habilidade para tratar com a organização e negociar com compradores. Com pouca importância na rede, essas trabalhadoras podem ser descartadas. Caso seja necessário exterminá-las, ou se forem detidas, são facilmente substituídas na organização.

$\mathrm{Na}$ concepção dessas mulheres, o trabalho no tráfico de drogas movimenta o mercado, o capital, mas não significa exatamente a sua realização como trabalhadora. A atividade serve apenas para atender às necessidades básicas de sobrevivência.

Feffermann (2006) lembra que o tráfico de drogas ganha espaço na macrossociedade, à medida que o Estado não consegue efetivar os direitos sociais. Sem concretizar o acesso aos direitos e à emancipação social, as organizações criminosas do tráfico demarcam seu território de forma crescente no contexto social, econômico e político brasileiro. Conforme foi possível verificar nas entrevistas de mulheres encarceradas, essa prática, que possui características de atividade laboral, significa a abertura de mercados e a possibilidade de estabelecer um comércio lucrativo.

Na opinião das entrevistadas, o trabalho legal possui uma significação simbólica, adquirida historicamente. Significa uma atividade necessariamente moral, aceita pela sociedade, especialmente no caso da mulher, que assume papéis, de filha, mãe e responsável pelo sustento e pela educação dos filhos.

De acordo com as entrevistadas, o tráfico de drogas ilícitas funciona de forma semelhante a uma empresa, com um sistema hierarquizado das ações, controle de território, concentração de poder e delegação das atividades. Tais características demonstram que são necessários vários requisitos para se classificar uma modalidade criminosa de crime organizado. Nesse modelo de organização, as mulheres são utilizadas na maioria das vezes apenas como pontes para fazer o transporte dentro dos territórios e beneficiar financeiramente o dono da boca/ponto de venda. 
Assim, o objetivo central deste artigo foi analisar a complexidade do trabalho das mulheres no tráfico de drogas, com a proposta de contribuir, de alguma forma, com as pesquisas sobre a condição feminina no mercado de trabalho e, de forma pretensiosa, quem sabe, poder se juntar a outros estudos sobre essa realidade.

\section{Referências}

ABRAMO, Laís. Inserção das mulheres no mercado de trabalho na América Latina: uma força de trabalho secundária? In: HIRATA, Helena; SEGNINI, Liliana (org). São Paulo: Senac São Paulo, 2007. p. 21-41.

BOITEUX, Luciana. WIECKO, Ela. (coord.). Tráfico de Drogas e Constituição: Um estudo Jurídico-Social do Art. 33 da Lei de Drogas Diante dos Princípios Constitucionais - Penais. Série Pensando o Direito. Brasília: SAL - Ministério da Justiça. 2009.

BRANDÃO, Marcilio. D. Ciclos de atenção a maconha no Brasil. Revista da Biologia. Vol. 13, N. p.1-10, 2014. Disponível em: http://repositorio.ufc.br/bitstream/riufc/19708/1/2016 . Acesso em janeiro de 2017.

BRASIL. Lei 11.343/2006. Disponível em: http://www.planalto.gov.br/ccivil 03/ ato2004-2006/lei/l11343.htm.> Acesso em abril de 2018.

Código Penal Brasileiro (2005). República Federativa do Brasil. Disponível em: http://www.planalto.gov.br . Acesso em abril de 2018.

Lei n. 6.368, de 23 de agosto de 1976. Disponível em: http://www2. camara.gov.br/legin/fed/lei/1970-1979/lei-6368-21-outubro-1976-357249 Acesso em abril de 2018.

CARNEIRO, Henrique S. As necessidades humanas e o proibicionismo das drogas no século $X X$. Outubro São Paulo, v. 6, 2002, p. 115-128. 
CASTEL, Robert. As metamorfoses da questão social: uma crônica do salário. 7. ed. Tradução de Iraci D. Poleti. Petrópolis: Vozes, 2008.

FEFFERMANN, Marisa. Vidas arriscadas: o cotidiano de jovens trabalhadores do tráfico. Petrópolis, Vozes, 2006.

HALBWACHS, Maurice. A memória coletiva. São Paulo: Centauro, 2006.

HECKERT, Cristiano. Rocha; FRANCISCHINI, Paulo, Graciano. Variações do Just-in-time na indústria automobilística brasileira. 1998. Disponível em: http://www.abepro.org.br/biblioteca/ENEGEP1998_ART169.pdf Acesso em junho de 2016.

INFOPEN - Levantamento Nacional de Informações Penitenciárias. Departamento Penitenciário Nacional. Brasil: Ministério da Justiça. Junho, 2016. Disponível em: $\quad$ WwW.justica.gov.br/news/ha-726-712pessoas...nobrasil/relatorio_2016_junho.pdf Acesso em abril de 2018.

KARAM, Maria Lúcia. Direitos Humanos, laço social e drogas: por uma política solidária $\mathrm{cm}$ o sofrimento humano. Conferência de abertura do VII Seminário Nacional de Psicologia e Direitos Humanos. Brasília, DF, nov. 2011. Promovido pela Comissão Nacional de Direitos Humanos do Conselho Federal de Psicologia (CFP) - Brasília. Disponível em: https://site.cfp.org.br/wp-content/.../07/Drogas-Direitos-Humanos-e-LacoSocial.pdf Acesso em janeiro de 2017.

HIRATA, Helena. O(s) Mundo(s) do Trabalho. Convergência e diversidade num contexto de mudança dos paradigmas produtivos. In: Seminário Educação e Empregabilidade. 1996. São Paulo. Disponível em: www.scielo.br/scielo.php?script=sci nlinks\&ref $=000231 \&$ Acesso em janeiro de 2017. 
LOCKE, John. Ensaio acerca do entendimento humano. São Paulo: Nova Cultural, 1999. P. 30-40.

LEMGRUBER, Julita. Cemitério dos vivos: análise sociológica de uma prisão de mulheres, 2 ed., Rio de Janeiro: forense, 1999. Disponível em: http://seer.ufrgs.br/sociologias/article/view/5515 Acesso em dezembro 2016

MARONNA, Cristiano. Proibicionismo ou morte? In: REALE JR, Miguel (Coord.). Drogas: Aspectos penais e criminológicos. Rio de Janeiro: Forense, 2005, p. 56.

MARX, Karl. O Capital. São Paulo: Nova Cultural. 1985. v.1 . Trabalho assalariado e capital \& salário preço e lucro. São Paulo: Expressão popular, 2008.

MONTOYA, Mário Daniel. Máfia e crime organizado. Rio de Janeiro: Editora Lumen Juris, 2007. p.140-150.

MOURA, Maria jurema de. Porta fechada, vida dilacerada-mulher, tráfico de drogas e prisão: estudo realizado no presídio feminino do Ceará. Monografia (curso de mestrado em políticas publicas e sociedade) Universidade Estadual do Ceará - Fortaleza-CE, 2005. Disponível em: $\leq \mathrm{http}: / /$ www.uece.br/politicasuece/dmdocuments/dissertacao. Acesso em janeiro de 2016.

NETO, Granato; NEI, Nelson. Exército industrial de reserva: conceito e mensuração. Dissertação (Mestrado em Mestrado e Doutorado em Desenvolvimento Econômico) - Universidade Federal do Paraná. 2013. Disponível em: https://acervodigital.ufpr.br/bitstream/handle/1884/30106/R\%20-\%20D\%20\%20NELSON\%20NEI\%20GRANATO\%20NETO.pdf?sequence=1 Acesso em junho de 2017. 
NOVAES, Elizabete David. Uma Reflexão Teórico-Sociológica acerca da inserção da Mulher na Criminalidade. In: Revista Sociologia Jurídica. $\mathrm{N}^{\circ} 10$, 2010. Disponível em: https://sociologiajuridica.net/uma-reflexao-teoricosociologica-acerca-da-insercao-da-mulher-na-criminalidade/ . Acesso em julho de 2016.

OLIVEIRA, Fernando Moreno Martim de. Redes narcotraficantes e integração paralela na região amazônica. Dissertação (Programa de PósGraduação em Relações Internacionais) - Instituto de Relações Internacionais, Universidade de Brasília, Brasília. 2007. Disponível em: http://repositorio.unb.br/handle/10482/4912 Acesso em janeiro de 2018;

POLLAK, Michael. Memória e identidade social. In: Revista Estudos Históricos, Rio de Janeiro, v. 5, n. 10, 1992. Disponível em: www.pgedf.ufpr.br/memoria\%20e\%20identidadesocial\%20A\%20capraro\%20 2.pdf. Acesso em outubro de 2016.

PROCOPIO Filho, Argemiro.VAZ, Alcides Costa. O Brasil no contexto do narcotráfico internacional. In: Revista Brasileira de Política Internacional. Brasília, num. 1, 1997, p. 75-122. DOI: http://dx.doi.org/10.1590/S003473291997000100004 .

Disponível em: www.scielo.br/scielo.php?script=sci_arttext\&pid=S0034$\underline{73291997000100004}$. Acesso em agosto de 2012.

SICA, Leonardo. Funções Manifestas e Latentes da Política de War onDrugs. In: REALE JR, Miguel (Coord.). Drogas: Aspectos penais e criminológicos. Rio de Janeiro: Forense, 2005, p.12-14

TELLES, Vera da Silva. Ilegalismos urbanos e a cidade. Novos estudos CEBRAP (online), n. 84, São Paulo, p. 153-175, jul. 2009. DOI: http://dx.doi.org/10.1590/S0101-33002009000200009 . Disponível em: http://www.scielo.br/scielo.php?pid=S010133002009000200009\&script=sci_arttext Acesso em agosto de 2016. 
TELLES, Vera da Silva. HIRATA, Daniel Veloso. Cidade e práticas urbanas: nas fronteiras incertas entre o ilegal, o informal e o ilícito. In: Estudos Avançados. v. 21, n.. 61 (2007). DOI: http://dx.doi.org/10.1590/S010340142007000300012 . Disponível em: http://www.scielo.br/scielo.php?script=sci_arttext\&pid=S010340142007000300012\&lng=pt\&nrm=iso\&tlng=pt. Acesso em maio de 2018.

RODRIGUES, Thiago. infindável guerra americana: Brasil, EUA e o narcotráfico no continente. São Paulo: Perspec. 2002, vol.16, n.2, pp. 102111. DOI: http://dx.doi.org/10.1590/S0102-88392002000200012 Disponível em: $\quad \leq$ http://www.scielo.br/scielo.php?script=sci_arttext\&pid=S010288392002000200012> Acesso em agosto de 2016.

ZAITCH, Damián. Trafficking cocaine: Colombian drug entrepreneurs in the Netherlands. Hague/London/New York: Kluwer Law International, 2002.

Recebido em março de 2018. Aprovado em novembro de 2018. 